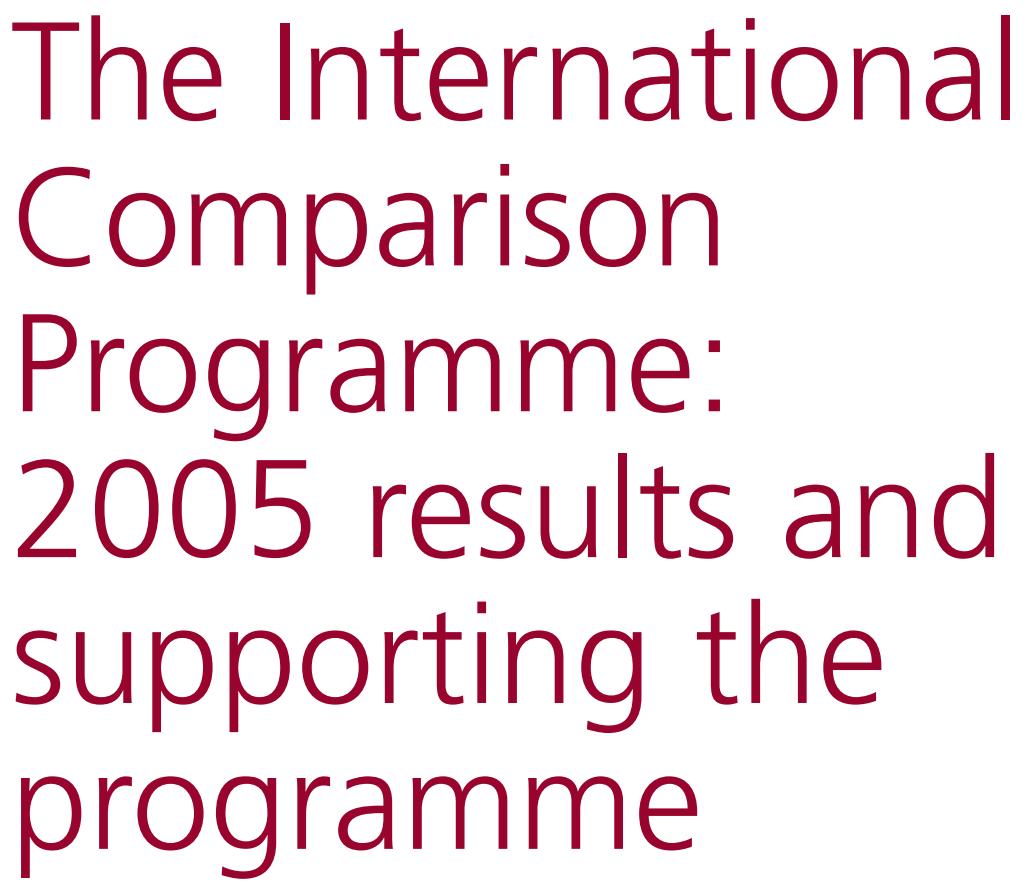

\section{The results of the International} Comparison Programme (ICP) were released by the World Bank in December 2007. The ICP is a global initiative to collect comparative price data and estimate relative price levels between countries. These figures allow international comparisons of real economic wealth to be made, and hence provide an essential tool for governments designing aid, trade and development policies.

This article explores the improvements made in the latest round of this initiative, and how the UK Government, through funding the Office for National Statistics via the Department for International Development supported the ICP in Africa - building a legacy of improvements both to the ICP as a whole and to price statistics and national accounts in many African nations. $\mathrm{n}$ this increasingly globalised world, it is becoming more and more important for governments, international organisations, businesses, researchers and individuals to make sound inter-country economic comparisons, be it to compare levels of expenditure in particular sectors (such as health or education), make reliable investment decisions or to assess progress towards improving living standards in developing countries.

Often the starting point for such analysis is to convert economic data in national currencies to a single currency for multicountry comparisons.

Exchange rates provide perhaps the simplest and most readily available method for converting currencies for the purposes of international comparisons, but they may in fact be misleading. By their very nature, exchange rates do not adjust for differences in price levels between countries. For example, developing countries tend to have relatively low prices for locally produced goods and services but higher prices for imported goods and services; hence, a unit of local currency has greater purchasing power within the country than in the global market. If only exchange rates were used to convert the gross domestic product (GDP) of various countries into a common currency for the purpose of making international comparisons, the GDP for developing countries would be likely to be underestimated.

What is required is a method for converting national currency data to a common basis, taking into account the differences in price levels between countries; the aim of the International Comparison Programme (ICP) is to provide such data.

The ICP is a worldwide statistical initiative which makes it possible to compare GDP in real terms - unaffected by differences in price levels between countries. This allows the user to assess relative economic welfare across countries and the relative size of a country's economy in real terms. The ICP achieves this by using Purchasing Power Parities (PPPs), calculated by comparing average prices between countries for a well-defined 'basket' of goods and services, as currency converters instead of monetary exchange rates. Box 1 explains the calculation of PPPs in more detail.

The data released through the ICP enable economic analysts to compare the levels of GDP and its major components between countries. International comparisons of this type are useful as the starting point in analysing productivity, living standards and poverty. One of the most high-profile uses of ICP PPP data is in the estimation of one-dollar-a-day poverty headcount figures. This information is an essential component for assessing the United Nations Millennium Development Goal of 'reducing by half the proportion of people living on less than a dollar a day between 1990 and 2015'; a target which was adopted in 2000 


\section{Box 1}

\section{What are PPPs?}

PPPs are price relatives that represent the rate at which the currency of one country needs to be converted into that of a second country to purchase the same volume and mix of goods and services. In essence, a PPP is simply the ratio of the price of a good or service in one country to the price of the same quantity and quality of the same good or service in another country.

For example, in country A, one kilogram of rice costs three euros while in country B, one kilogram of rice costs four dollars. The PPP between these items would be 0.75 (three divided by four). This means that for every dollar spent on rice in country $B$, it would be necessary to spend 0.75 euros in country $A$ to obtain the same quantity of rice.

The ICP expands this method to calculate PPPs which compare average prices between countries for a well-defined 'basket' of goods and services covering the whole economy, from basic food to electronics, housing, education, healthcare and even the construction of buildings and the cost of machinery and equipment. The result is normally expressed in index form with the USA or the World equal to one.

by all UN member states.

The ICP was established in 1968 in response to the UN Statistical Commission recommendation that a worldwide system to measure the purchasing power of currencies be developed. The first round of the ICP was carried out for 1970, based on data for ten countries. Further rounds in $1973,1975,1980,1985$ and 1993 saw the coverage of the programme increase to 118 countries. The current ICP round, which produced results for 2005, involved 146 countries from six regions around the world.

The 2005 round of the ICP also introduced changes in methodology that represented a significant step forward when compared with the 1993 programme, particularly in respect of the methods used to link the regional programmes together to produce global results. This new methodology, called the ring comparison, was developed specifically to link the regional PPPs without changing the relative results within a region. In simple terms, it involved a selection of representative countries from each region collecting prices data for a common list of core global products, in addition to their regional surveys. The results of this additional survey were then used to calculate linking factors' used to link regional PPPs into a global data set.

The 2005 round of the ICP marks a significant milestone in the development of African price statistics. The increased involvement of Africa is significant; the 1993 round saw only 22 African countries included in the results, but the 2005 round produced results for 48 countries. The new ICP data have various policy implications: for example, in the UK, the Department for International Development (DFID) uses PPP-adjusted gross national income per capita figures for aid allocation. The increased coverage of this round will mean that such decisions can be made on a sound basis. This round of the ICP also marked the first time that an African institution - the African Development Bank - took the

\section{Figure 1}

\section{Regional shares of global GDP}

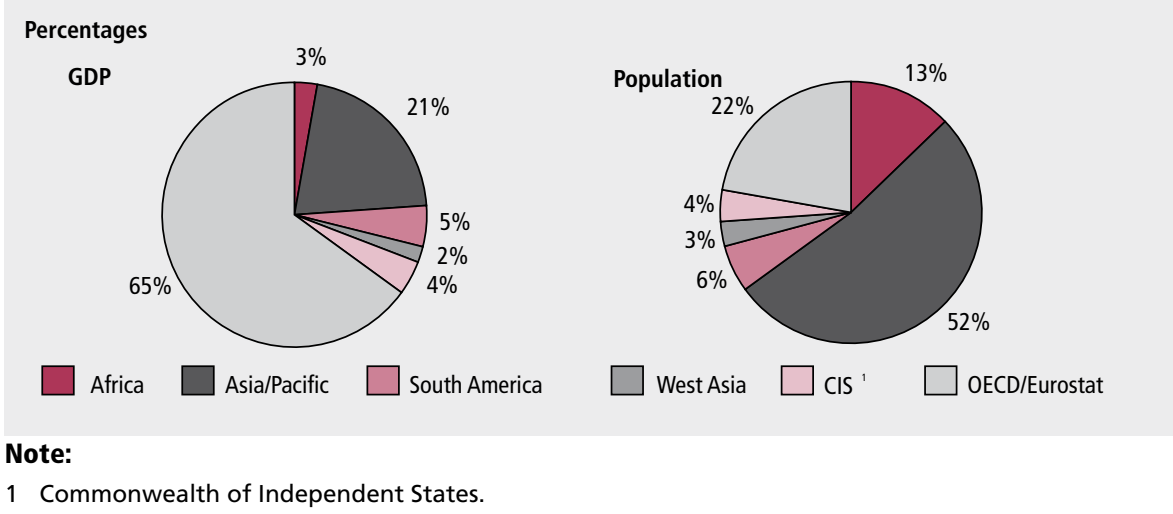

role of regional coordinator for the Africa region, leading on all aspects of the programme.

\section{ICP global results}

The ICP Global Office at the World Bank released global results in December 2007; these are available at www.worldbank.org/data/icp This followed the release of regional results by each of the ICP regional coordinators.

\section{UK position}

Since the results from the ongoing Organisation for Economic Co-operation and Development (OECD)/Eurostat PPP programme have been integrated into the overall ICP, the UK's position within the results is much as expected. The UK ranks sixth in the world for total GDP, a 3.5 per cent share of global GDP, and is 20th in the ranking for GDP per capita.

The UK is amongst the 12 economies which together account for more than two-thirds of the world's output, seven of which are high-income economies (the USA, Japan, Germany, the UK, France, Italy and Spain), and five are developing or transitional economies (China, India, Russia, Brazil and Mexico).

The UK is also one of the five richest economies for per capita measures of consumption (actual individual consumption plus individual government consumption), which provides a way to compare average living standards. By this measure, the five richest economies are Luxembourg, the USA, Iceland, the UK and Norway.

\section{Other points of interest}

The relative wealth of China is one issue that has appeared in the press following the release of ICP results. The ICP results show that China's economy is smaller (and poorer) than previous estimates, which were extrapolated from a bilateral comparison of 1986 prices between China and the USA, suggested. Indeed, these previous estimates overestimate the size of China's economy by 40 per cent when compared with ICP results. The ICP global results show that China accounts for 9 per cent of global GDP and, although this is perhaps lower than anticipated, it is still the second highest share for a single country - the highest being the USA at 23 per cent.

Figure 1 displays how real GDP is split between regions and the estimated share of global population in those regions. As may be expected, the OECD/Eurostat 
region accounts for a high percentage of global GDP - 65 per cent - and is home to approximately 22 per cent of the global population. Africa accounts for only 3 per cent of global GDP and is home to approximately 13 per cent of the global population. The population of the OECD/ Eurostat region is therefore just under twice that of Africa, but it accounts for 22 times the GDP. In the case of Africa, the fact that 13 per cent of the world's population accounts for only 3 per cent of its GDP is an indication of the relatively low level of economic welfare in the region. The other regions which also account for relatively low proportions of global GDP - Commonwealth of Independent States, South America and West Asia - all have significantly smaller populations than Africa.

The USA, China, Japan, Germany and India account for nearly half of the world's GDP. Asia/Pacific accounts for 21 per cent of global GDP, about two-thirds of which is accounted for by China and India. Asia/ Pacific, however, is the region with by far the highest population, and therefore GDP per capita is the second lowest (see

Figure 2). China itself ranks second in the world for GDP but 86th for GDP per capita. The Asia/Pacific share of global GDP (21 per cent) is similar to that of the USA (23 per cent) and the EU (24 per cent).

GDP per capita results show that the bottom 20 countries, and 28 out of the bottom 30 countries, are in Africa. The African country with the highest level of GDP per capita is Gabon, 47th in the world ranking, and the lowest is the Democratic Republic of Congo, 146th, and the lowest ranking globally. Figure 2 shows the real GDP per capita for each of the ICP regions, and an average for the EU countries. The chart clearly shows the relatively low position of countries in Africa. The average GDP per capita for the world is US $\$ 8,900$ (per annum); 17 countries have GDP per capita of less than US $\$ 1,000$, all of which are in Africa, and three (Democratic
Republic of Congo, Liberia and Burundi) have per capita GDP levels of less than US $\$ 500$.

This quick high-level analysis of the global results highlights the main stories and shows the importance of the data produced by the ICP for making international comparisons.

\section{Supporting the ICP: organisational partnerships}

The success of this round of the ICP has been a credit to the effective collaborations between different international, regional and national organisations. The ICP is a highly complex international programme that by its nature calls on wide-ranging input from many different parties. The work involved for countries and regional coordinators especially can be challenging, particularly where statistical capacity and the accompanying available resources at a national level are limited.

In order to ensure delivery of the global and regional ICP results, and to relieve the burden on regions/countries where resources are stretched, this round has seen a number of 'partnerships' between regional programmes and National Statistical Institutes (NSIs) from outside that region. One such arrangement is the Office for National Statistics (ONS) ICP Africa Support Project, funded by DFID. ONS supported the ICP in Africa through the provision of direct technical assistance as necessary, with the aim of helping to ensure the successful participation of Africa in the global ICP and the facilitation of longerterm statistical capacity building.

Although this article focuses on the support given by ONS to ICP Africa, there were three other partnership arrangements in place during the 2005 ICP which were similar in motivation but different in the detailed delivery. These partnerships arose for different reasons, in different sets of circumstances and followed different constitutions, but were alike in their goal of supporting the regions in producing high-

\section{Figure 2}

Regional GDP per capita per annum

US dollars

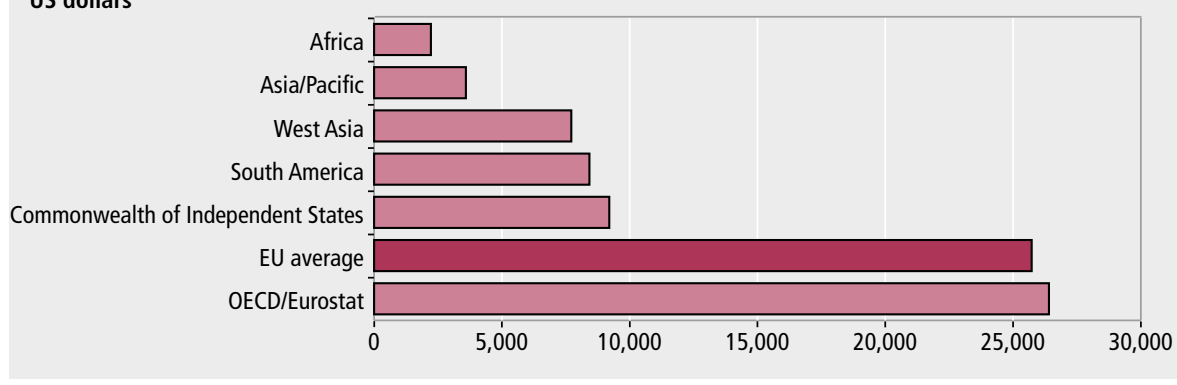

quality results. These arrangements were:

- The Institut National de la Statistique et des Études Économiques - France (INSEE) provided support to francophone nations in Africa

- The Australian Bureau of Statistics (ABS) provided technical and strategic advice to the Asian Development Bank (ADB) and essentially took responsibility for building a specific component of the ICP - in this case the item list for the Asia/Pacific region

- Statistics Canada took on the role of joint regional coordinator for the South America regional programme in addition to providing most of the finance for the programme

\section{The ICP Africa support project}

From March 2005, ONS has been managing a three-year DFID-funded project - the ICP Africa Support Project. The overall goal of the project is to facilitate a positive outcome to the ICP in Africa and to effectively exploit ICP Africa as a catalyst for sustainable statistical capacity building in the longer term.

From the start of the global programme, the UK government was already a major donor to ICP Africa and more generally to statistical capacity building. However, DFID also agreed to fund this additional project under the philosophy of providing a flexible resource. The project was set up to have as few strings attached as possible, in the anticipation that its resources could be used more effectively to ensure successful country participation in the ICP and to increase local statistical capability. It was thought that, for a relatively low expenditure, a project of this type would be cost-effective and would add significant value to the ICP and capacity building work. The project would also aim to ensure that there is a lasting legacy from this round of the ICP in Africa.

The project has worked in close partnership with the African Development Bank (AfDB). Through the provision of technical assistance directly to the AfDB, to African countries, and at regional and subregional workshops, the project has contributed to Africa's successful inclusion in the ICP global comparison. ONS has provided support directly to 18 African countries, focusing on the two main requirements for the successful computation of purchasing power parities for the ICP: the collection of good-quality price data and the effective exploitation of all available national accounts and 
household budget survey information for use as weights.

Specific ICP support provided by the project has encompassed:

- technical assistance directly to countries. In 2005, technical assistance was provided through missions to Ghana, Nigeria, Angola, Swaziland, Tanzania, Kenya and Zambia which assessed overall ICP understanding and readiness as well as the basic quality of price survey frameworks, price collections and price data. In 2006, ONS consultants worked with Botswana, Swaziland, Angola, Kenya, Lesotho, Malawi, Zambia, Uganda, Zimbabwe, South Africa, Namibia, Rwanda and Tanzania to assist with the construction of expenditure weights, quality assurance of estimation techniques used and with the compilation of a GDP estimate for the reference year 2005. In 2007, support on ICP national accounts has also been provided to Sao Tome and Principe, Cape Verde and Equatorial Guinea

- regional/subregional support. This included employing expert consultants to attend and contribute to regional and subregional seminars on prices and national accounts, providing direct support to subregional organisations in order to assist them in completing their ICP objectives, assisting with the validation of ICP data and supporting the AfDB on the compilation of results and production of the preliminary and final publications

- strategic guidance. Through 'partnership meetings' with AfDB, ONS and the World Bank, the project provided input into discussions on progress, strategic direction, methodology and future support

Work on the project's second objective (to exploit the investment in ICP Africa as a catalyst for sustainable statistical capacity building in the longer term and to contribute to the goal of an improved and sustainable evidence base for country-level decision making) has focused on four main areas:

- facilitating improvement in national consumer price indices (CPIs) through the integration of ICP methods

- supporting the harmonisation of CPIs across African subregions
- producing a supplementary handbook to the ILO manual on Consumer Price Indices, focusing on the practical measurement issues confronted by the developing world, and

- exploring the use of data collection technology to improve African CPIs

\section{How the project helped}

The ONS ICP Africa Support Project has contributed significantly to the ICP Africa programme and represents an effective method of providing support to such initiatives. Some key advantages of the project in relation to the ICP support it has given during this round were:

- the project provided an additional and distinct resource for ICP Africa, allowing AfDB and/or the ICP Global Office to focus on other priorities

- the nature of the project meant that its resources were often more flexible, enabling direct support to countries at short notice and with minimal administrative burden

- the project's location within ONS meant that it could draw on the experience of UK statisticians in various areas, including prices and national accounts as well as from those working on the OECD/Eurostat PPP programme and on the ICP through the UK's involvement as a 'ring' country

- the project provided the capacity for experienced internationally acclaimed experts to attend regional and subregional ICP seminars/workshops. In their independent role, these consultants were able to add significant value to the discussions and provide helpful insights based on their experiences

- the project led to the sharing of expertise and knowledge between organisations and also informal training when experienced consultants worked directly with countries

- part of the governance of the project consisted of regular meetings with AfDB, the ICP Global Office and INSEE. These meetings proved an effective method for sharing information, assessing progress and discussing the future work programme

- the project operated on a number of levels, providing specific technical support to countries and also facilitating the sharing of ideas and planning at a more strategic level through a four-way meeting with the World Bank, INSEE and AfDB
- the UK, through ONS, was involved in the ICP on many levels, as a ring country, as ring coordinator (for the OECD/Eurostat region), as a member of the ICP Executive Board, and through the management of the ICP Africa Support Project. This wideranging involvement greatly facilitated the sharing of information across the programme. The presence of ONS on the ICP Executive Board, in particular, provided a stronger voice for ICP Africa which was helpful when addressing Africa's concerns and providing the Board with feedback on the practical problems being confronted by ICP participants in Africa

The project committed the majority of its resources towards supporting the ICP, but alongside this it was also able to carry out some projects specifically aimed at statistical capacity building. The objective of this work was to add to the sustainability of the investment in the ICP (both in terms of money and expertise) in order to make advances in statistical capacity that would leave a lasting legacy. Work in this area focused on:

- a study of the feasibility of integrating ICP components into national CPIs and the subregional harmonisation of CPIs, in order to inform future direction

- a supplementary handbook (currently under development) to the UN Manual on CPIs, focusing on providing practical advice to developing countries

- two pilot studies into the use of handheld computers for the collection of prices data, carried out in Nigeria and Uganda

Aside from these specific projects, the general transfer of knowledge from ONS staff and consultants to colleagues at African NSIs also took place.

\section{Conclusions}

The 2005 round of the ICP represents a significant step forward in terms of the measurement of economic welfare. The methodology, coverage and governance of this round of the ICP were all developed following the 1993 round and consequently the results are more comprehensive and should be far more reliable as a basis for cross-country comparisons. The data will no doubt be widely used as a starting point for economic research and policy analysis and most particularly in the measurement of global poverty. 
The partnership arrangements in place during the 2005 ICP round have, in general, been of great benefit to all parties involved and have been a significant contributing factor to the delivery of regional and global results.

The type of partnership arrangement that is the most effective may vary from region to region. In Africa, the regional coordination by AfDB was strong, and needed to be, given the geographical size and diversity of the African continent. The ONS support project was particularly effective in Africa as, although it was not merely reactive, it was able to provide a flexible resource which could be called upon to solve pressing and unforeseen issues and provide specific technical assistance. Alternatively, in South America, the relatively small number of countries involved (ten countries compared with over 40 in Africa) and limited resources at the Economic Commission for Latin America and the Caribbean (ECLAC) meant that Statistics Canada took on more overall responsibility for the coordination of the regional programme.

Some of the arrangements have been managed more formally than others; for example, the ONS model involved a formal arrangement and memorandum of understanding between the supporting organisation and the regional coordinator. ABS and INSEE methods were managed more through existing relationships, where operational arrangements were already in place on the ground, and more informally. In the case of South America, there were no formal arrangements in place between ECLAC, Statistics Canada, NSIs and the World Bank.

In all cases, the success of such arrangements is highly dependent upon effective working relationships between staff across organisations, particularly those providing the support and the regional coordinator. In the case of the ABS support, the relationships with $\mathrm{ADB}$ were to a large extent already well established prior to the ICP, whereas the relationship between ONS and AfDB had to be developed during the early stages of the programme.

As well as benefiting regional coordinators and countries through providing additional support, there are also benefits to the organisation supplying the assistance. Such arrangements can be a good opportunity for NSI staff to gain experience working on the ICP and with other NSIs, regional and international organisations. These arrangements can therefore be seen as capacity building both to the organisation receiving the support and the organisation providing the support.

On the whole, the partnership arrangements have contributed significantly to the aim of the ICP to bring about advances in the capacity and capability of both the individuals and the organisations involved in the programme within regions. In the case of South America, however, it remains to be seen whether the project has contributed as much to lasting statistical capacity, as the nature of this level of support would suggest less grass-roots capacity building. During the course of the programme in Africa, there was a clear capacity building objective; this was not the case for South America.

The ONS support project also focused on the building of longer-term statistical capacity and on the sustainability of the significant investment in this round of the ICP. There is still some work to do to ensure that the knowledge, expertise and statistical capacity that have been enhanced through the ICP is not diminished after the end of this round; perhaps this should also include the continuation of the strong partnerships which have been developed.

A feasibility study commissioned by ONS and AfDB in 2007 looked into the possible benefits to national CPIs (in terms of quality, timeliness, relevance and so on) of greater synergies between CPI and ICP exercises (see Astin 2007). This study concluded that national CPIs can draw benefits from the ICP in terms of:

- geographic coverage

- outlet-type coverage

- methods of outlet selection

- the use of more detailed structured product descriptions

- improved methods for data validation and editing

- improved computer systems

- improved documentation, and

- better standards of staff training and increases in CPI staff resources

The integration of CPI and ICP product lists - increasing the number of items included in both the CPI and ICP lists - would also lead to significant benefits in terms of efficiency of any future ICP rounds with more use of data collected for the CPI. Also, increasing synergies between the two exercises may encourage the statistics office to update the CPI list to make it more relevant to present-day purchasing habits. Initial feedback from countries where the ICP Africa Support Project provided assistance, and from impartial observation, suggests that the ICP has led to seemingly sustainable improvements to national CPIs, but only time will tell.

Looking back on the ONS experience raises the question of whether any lessons were learnt during the course of the project which may have implications for future partnerships for the delivery of technical assistance. One important point to make in this context is that the ONS support project was only initiated in March 2005, at which time the planning process was complete and the ICP already into its data collection period. The usefulness of the project may have been further enhanced if it had been in place earlier in the process and could therefore have provided support throughout the full life of the programme. An earlier start would certainly have better facilitated forward planning at the initial stages where ONS involvement in ICP Africa tended to be less proactive and more reactive, before a coordinated longer-term and forwardlooking work programme was in place. The overall success of the various partnership arrangements during the 2005 round is a strong driver to see similar arrangements in place next time and to ensure that they are implemented early for any future rounds of the ICP.

\section{CONTACT}

国elmr@ons.gsi.gov.uk

\section{REFERENCES}

African Development Bank (2007) 'First Results of the International Comparison Program for Africa'.

Astin J (2007) 'The value of ICP Participation in Producing Sustainable Benefits for National Consumer Price Indices: An Illustrative Example', African Statistics Journal.

OECD (2006) 'OECD member countries' population 1985-2005 (thousands and indices: $2000=100)^{\prime}$, Labour Force Statistics, 2006 edition.

United Nations Department of Economic and Social Affairs, population division (2005) 'World Population Prospects: The 2004 Revision'.

World Bank (2007) 'Global Report: International Comparison Program'. 